\title{
Stress testing and consolidated supervision as instruments for enhanced risk-oriented monitoring of banks' activities
}

\author{
Hamid Alibeiki \\ Master of Science in Economics, University of Yazd; Professional Lecturer at Imam Javad University, Iran.
}

\section{Maksym Samsonov}

$\mathrm{PhD}$, Cash Circulation Department of Sumy Region, National Bank of Ukraine, Ukraine.

\begin{abstract}
Today one of the key tasks of economic development in different countries of the world is the ensuring of stable functioning of the financial sector in general and the banking system in particular. The processes of consolidation of bank capital, complication of banking business technologies, increasing banks' risk appetite for risk concentration and speculative operations, and increasing systemic financial risks require the attention of financial sector regulators to identify potential imbalances in the activities of banks. One of the central places in the banking regulation system is off-site banking supervision, in particular, remote monitoring of the activities of banks. A series of reforms aimed at introducing macro-prudential banking supervision in accordance with the requirements of the Basel Committee on Banking Supervision has been initiated, but given the low transparency of domestic banks and the lack of existing mechanisms for risk taking into account in supervisory work, the reform of the existing system of remote monitoring on the basis of risk-oriented approach.
\end{abstract}

Key words: risk-oriented monitoring, banking supervision, banking system, financial sector.

JEL Classification: G21, G29.

(C) The Authors, 2017. This article is published with open access at ARMG Publishing.

\section{Introduction}

The introduction of differentiated modes of remote risk-oriented monitoring of the activities of banks requires revision of the existing supervisory tools. According to the proposed regimes, the basic monitoring mode is characterized by the lowest intensity of the application of surveillance actions and measures. This is due to the fact that banks that have fallen into the «base» monitoring zone differ from other banks with a low level of risk profile of the banking business and insignificant influence on the stability of the banking system. In order to comply with the principle of cost-effectiveness of the supervisory process, based on the basic regime of remote risk-based monitoring, in our opinion, a mechanism should be put in place for self-regulation of banks 'activities and strengthening of banks' responsibility for the process and results of conducting banking business.

According to the author's proposals, the enhanced mode of remote monitoring of banks activity is characterized by increased attention of supervisors to banks characterized by a high level of aggregate risk profile of the bank and an average (or significant) degree of influence on the country's financial stability. This, in turn, creates the preconditions for using an extended set of monitoring tools. It should be noted that the higher developed stehklder's model of remote monitoring, it is recommended to use only the banks of the basic monitoring mode.

With the increasing urgency of solving the problem of ensuring financial stability of the country and the resilience of banks, the approach to determining the ability of the banking system, and banks in particular, to withstand stressful situations and maintain current viability (solvency), in particular stress-testing tools, is becoming increasingly important.

The most widespread practice of stress testing was received during the crisis period as one of the key risk management tools both at the macro (level of supervisory bodies and international financial institutions) and at the micro level - the level of banks. In particular, the methodological principles for the implementation of stress testing have been reflected in a number of international instruments - «Recommendations for the implementation of best practices in stress testing and supervision» developed by the Basel Committee on Banking Supervision (Principles for Sound Stress Testing Practices and Supervision) «Analytical Toolkit for the Program Financial Sector Assessment «(Analytical Tools of the FSAP) proposed by the IRF and national ones - Methodical recommendations on the procedure for conducting stress testing in Ukrainian banks and 
Methodological recommendations for the organization and functioning of risk management systems in banks of Ukraine, developed by the National Bank. The use of stress testing tools is called:

$>$ Macroeconomic level - the degree of propensity of groups / systems of banks to risk in the scale of the financial system of the country and, accordingly, to structurally determine the vulnerability of the national banking sector to «stressful situations»;

$>$ at the microeconomic level - to assess the degree of bank's risk appetite in order to develop further corrective measures, to determine the level of risk of the bank and its structure, the maximum level of losses (including profits and / or capital).

\section{Methods and results}

Stress testing is a method of quantification of risk, which consists in determining the value of the unmatched position that affects the bank on risk and in determining the shock value of the change in the external factor the exchange rate, interest rate, etc. A combination of these variables gives an idea of the amount of losses or revenues that a bank will receive if events are developed based on assumptions. Stress testing is widely used to assess credit risk, liquidity risk, currency risk, interest rate risk and asset value. The objective of stress testing is to assess the risks and determine the ability to withstand shock in the financial market.

The most common objects of Stress testing are: a sharp change in interest rates on internal or external borrowings, loans, securities, etc; significant fluctuations of exchange rates; credit risk in loan portfolios; sharp changes in volumes and structure of capital of a financial institution, mortgage collateral value; decrease in liquidity and bank default probability; the probability of a systemic risk arising from a sharp decrease in liquidity or loss of capital, etc.

As the basic risk factors, the National Bank recommends the following: 1) macroeconomic indicators: stability of the economic situation (economic decline, radical change in the economic development vector, defaults of first-class companies-borrowers, etc.); significant fluctuations of the exchange rate of the national currency; openness and accessibility of the interbank market; the level of political and international stability; stability of financial markets, including Opportunity to counteract speculative attacks; changes in interest rates, such as LIBOR, discount rates, etc .; the possibility of impairment of property that was provided to provide collateral for bank lending operations (in particular, because of falling prices in the real estate market, the crisis of certain sectors of the economy, etc.); volatility of prices for energy resources; 2) microeconomic indicators: the ability of the bank to access external sources of liquidity maintenance; Bank's competitive position (determined by SWOT analysis as a generalized assessment).

The study of the peculiarities of using the tools of stress testing in domestic observation practice gives grounds to note its fragmentary nature. In particular, based on these annual reports of the National Bank, starting from 2007, the National Bank for the purpose of exercising prudential supervision over the banks starts using stresstesting calculations, and in 2009, in order to determine the planned amount of capitalization of banks by investors, including . and the state. Among the features and, as a rule, the main drawbacks of the domestic supervisory practice of stress testing, it should be noted:

- First, the results of stress testing of banks for the National Bank serve only as a subsidiary instrument for analyzing its financial position, and are not used as an independent supervisory tool for the purpose of adopting appropriate prudential measures;

- Secondly, there is a low level of transparency as a result of stress testing, as well as a direct methodology for its implementation. Thus, in annual reports of the National Bank, only the fact of conducting calculations of stress tests without proper detail is indicated;

- Thirdly, from the standpoint of stress testing methods - sensitivity analysis (study of the degree of vulnerability of the bank / banks to the change of one risk factor) and the scenario method (study of the degree of vulnerability of the bank / banks to the change of several risk factors simultaneously, that is, the corresponding scenario) - the analysis of the bank's sensitivity is used only for certain risks (credit, currency, interest rate and liquidity risk, etc.);

- Last, for domestic supervisory practice, it is typical to use the approach to implementing stress-testing on the «top-down» principles, which is the simplest, and therefore least, practically meaningful approach.

One of the ways to overcome these shortcomings can be to apply the practice of stress testing at the micro level, that is directly banks. Effective use of recommendations developed by the National Bank for the implementation of stress testing by Ukrainian banks (focusing on specifying the goals and objectives of stress testing, identifying the basic macro and micro risk factors, types of testing risks, methods, stages, periodicity 
of implementation, etc.) is complicated by our view, the uncertainty of macroeconomic scenarios and projections, and hence the heterogeneity of the methods used by different banks, and the inequality of the results of settlements between individual banks. Based on the above, there is an objective need to develop an integrated approach to the implementation of stress testing, in particular the combination of «top-down» and «bottom-up» principles.

In the context of the author's proposals regarding the use of stress testing as one of the key tools of the enhanced regime of remote risk-oriented monitoring of the activities of banks in Ukraine (Fig. 1), we propose a number of the following principles for its use by the respective banks:

- obligatory implementation of the practice of stress testing by banks - objects of the strengthened monitoring regime by the National Bank, and as a result, in case of non compliance with such a requirement, there are grounds for applying the National Bank of measures of influence for violation of banking legislation. It should be noted that among recent researches of world rating agencies the fact of the extraordinary importance of incorporating stress testing into regulatory requirements is substantiated, which significantly increases the likelihood of its use by banks as an integral element of internal risk management systems and a key component of business planning and management decision making;

- the principle of consistency, which is ensured by time-coordinated actions and measures on conducting stress tests implemented by banks - objects of the strengthened monitoring regime by the National Bank, and provides for the definition of specific periods of implementation of the practice of stress testing;

- the principle of independence and independence, which means using the stress testing procedure not as an auxiliary, but as an independent tool for remote risk-based monitoring of the activities of banks, and the objectivity of stress testing, the lack of asymmetry of information or the influence of stakeholders;

- the principle of promising and substantiated, which envisages the formalization of the National Bank of macroeconomic forecasts of the development of the banking system in the form of three main scenarios (basic, optimistic and pessimistic) and bringing them to banks - monitoring objects as the source database, which, in turn, allows banks to assess their own risk profile taking into account a certain time horizon;

- the principle of transparency, which is ensured by the publication of both methodology and results of stress testing;

- the principle of adaptability, which is ensured by the adaptation by banks of objects of monitoring of macroeconomic scenarios by means of their transfer into individual risk parameters taking into account institutional (for example, availability of foreign / state capital) and functional features (bank's business strategy, risk-appetite, etc.) business;

- the principle of hierarchy, which means hierarchical interaction between the National Bank and the banks objects of monitoring. 


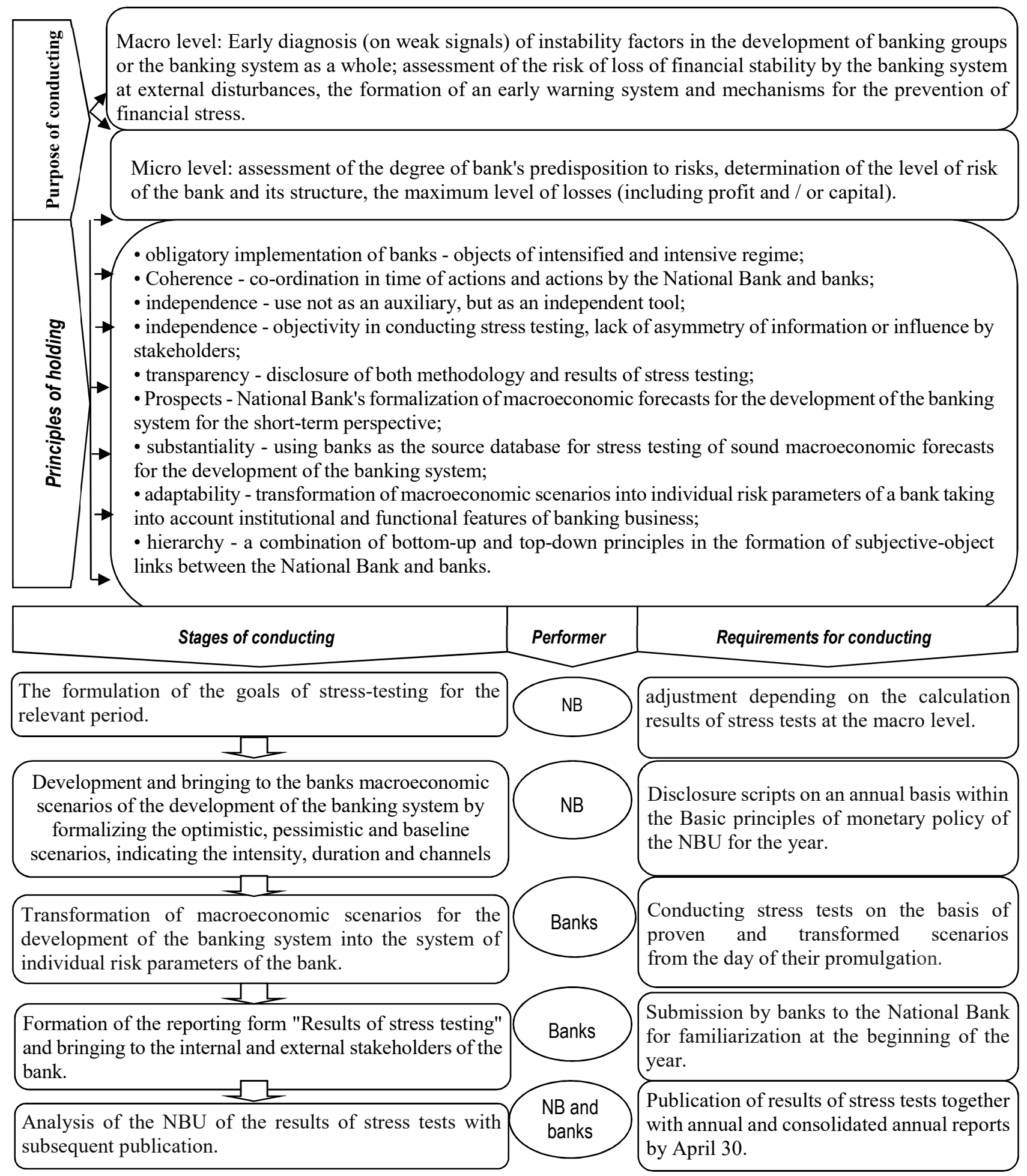

Fig. 1. Structural and logic scheme of carrying out stress testing of banks as a tool for enhanced remote risk-based monitoring over the activities of banks

In accordance with the proposed algorithm for implementing the practice of stress testing as an instrument of the enhanced mode of remote monitoring of the NBU by banks, the key position is the development and submission to the banks by the National Bank of the macroeconomic scenarios of development for the banking system by disclosing scenarios within the framework of the Basic Principles of the monetary policy of the National Bank to the corresponding A year followed by informing and agreeing scenarios by the Verkhovna Rada of Ukraine. At the same time, during the macroeconomic modeling, the importance of the intensity of stress events within the relevant scenario and the main channels of transmission of macroeconomic shocks becomes of paramount importance. In our opinion, when developing the macroeconomic scenarios, the factors to be taken into account by the National Bank include the relationship between the country's risks and key risks of the bank, which are realized through financial instruments used by a separate bank; links between the 
financial and public sectors of the economy, interconnections and the existence of reverse effects between the real and financial sectors of the economy (worsening macroeconomic constraints hinders the development of bank lending, which in turn negatively affects GDP growth of the country), etc.

One of the main and labor-intensive aspects of the banks - objects of the enhanced mode of remote monitoring of the stages of the practice of stress testing is the transformation and transfer of the scenario of the development of the banking system into an individual system (map) of risks. This requires banks to have appropriate information technology and modules, responsible persons (usually an asset and liability management committee) in the bank and regulated internal procedures and policies. As the direct objects of stress testing, it is recommended to use indicators of the regulatory, economic and accounting capital of the bank, liquidity and cash flows, market risks of the bank. According to the results of the stress tests, the formation of the appropriate reporting form is foreseen for further familiarization with the National Bank and senior management of the bank. In our opinion, in the context of the need for increased transparency of banking activity and stimulation of market discipline, the procedure for publicly disclosing the results of stress testing by banks - objects of remote monitoring, which should be implemented in the system of financial reporting of Ukrainian banks, is necessary.

Thus, the introduction in practice of supervision of banks - objects of the enhanced monitoring regime of the mandatory stress testing procedure with subsequent public disclosure of its results is consistent with the principle of cost-effectiveness (since it does not apply to all banks) and is aimed at improving the quality of internal risk- management of such banks, and, consequently, increase of financial stability of the country.

Along with the procedure of mandatory stress testing, we offer as another tool for enhanced monitoring of the remote monitoring of banks using separate elements of consolidated supervision. In today's conditions of consolidation of banking and parabank sector assets, the proliferation of mergers and acquisitions, as a consequence, the creation of banking groups and the transformation of part of the banking business into other business structures in the form of affiliated and affiliated companies, the need for banking supervision on a consolidated basis is recognized by most countries the world. This is primarily due to the «credible» nature of the banking activity and the work of the bank with attracted capital, which requires the most recent conduct of a risk-safe business from the point of view of the interests of its depositors and creditors. In connection with the commencement of the implementation processes in the domestic banking practice of consolidated banking supervision and the formation of a corresponding regulatory field by the National Bank, the development of methodological support for the implementation of such supervision becomes of particular importance. In the context of this dissertation research, the issue of remote monitoring in the system of banking supervision over the activities of banks - participants of banking groups remains unclear. Before turning to specific recommendations and author's position in resolving this issue, consider the existing requirements put forward by the domestic supervisor to the banking groups and their participants and are subject to control by the National Bank (Fig. 2).

The legislative basis for the implementation of consolidated banking supervision by the National Bank is a series of legal acts in relation to the identification and recognition of the banking group (On the procedure for the identification and recognition of banking groups), the procedure for submitting and disclosing the ownership structure of the banking group and directly regulating its activities, in $t$.ch submission of financial and statistical reporting. It should be noted that from the side of the NBU, both qualitative and quantitative requirements are put forward to the banking groups. The main feature of qualitative requirements is the time period of their application, in particular, they take place at the stage of identification of the banking group, with its subsequent recognition and determination of the responsible person. 


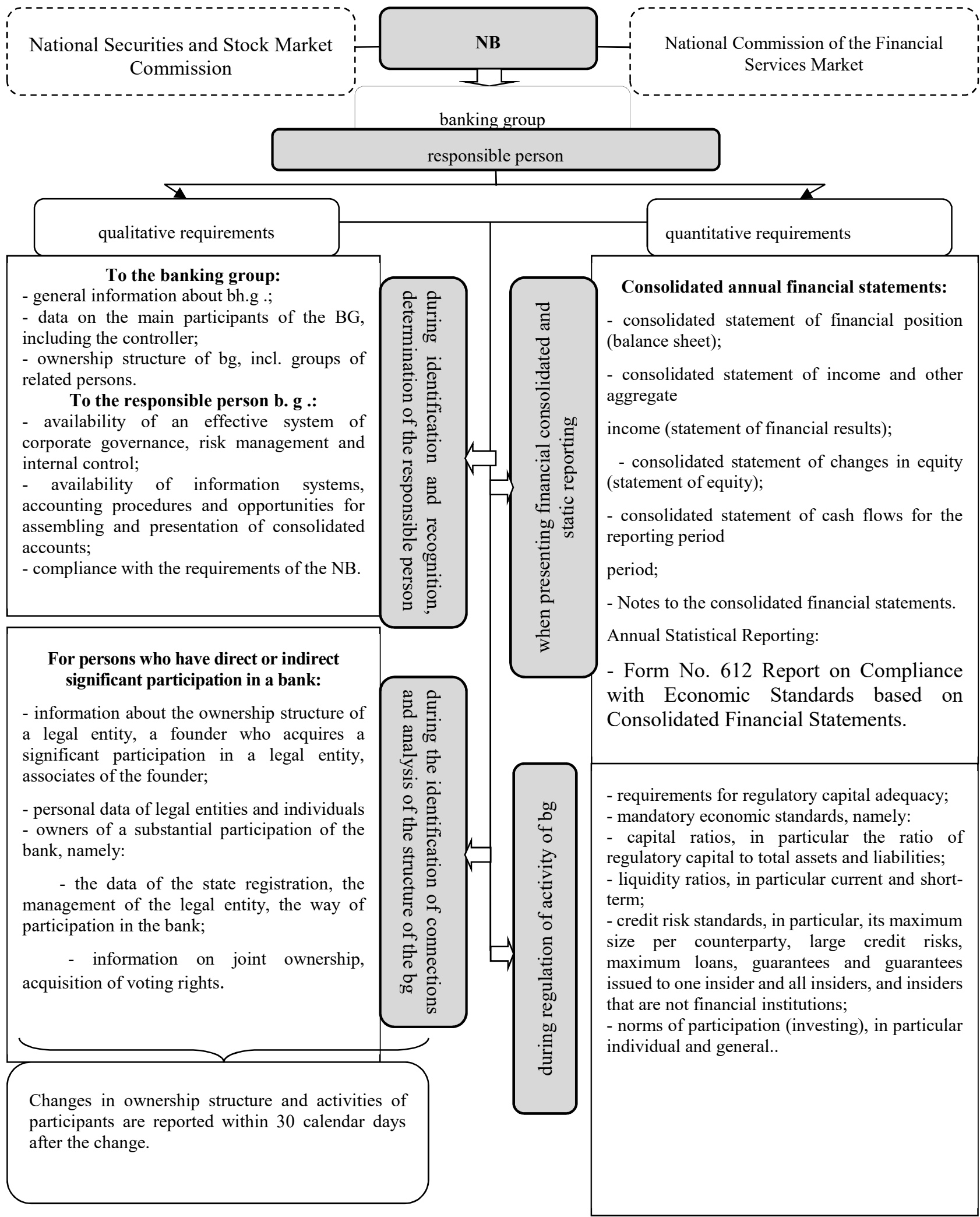

Fig. 2. Instrumentation by the National Bank of Consolidated Banking Supervision (as of early 2013)

The establishment of qualitative requirements is intended first of all to find out the general organizational information concerning the banking group and to determine the main interrelations of the group. In our opinion, the key shortcoming of the existing qualitative requirements for the banking group is the lack of periodic monitoring by the National Bank of the quality of the corporate governance system, risk management system and internal control, which becomes of particular importance in connection with the generation of specific risks during the activities of the banking group. Thus, such claims are addressed only to the responsible person of the banking group and only at the time of its determination - provided that only the 
structure of ownership or activities of the participants of the banking group is changed, information is submitted to the National Bank, which, accordingly, has an irregular nature. Consequently, the actual absence of monitoring on a regular (periodic) basis by the National Bank of the banking group risk management system and other important qualitative components of its policy can be argued.

Considering the quantitative requirements of the National Bank to banking groups, we note that the fundamental basis for consolidated supervision is, on the one hand, consolidated financial statements, which are submitted on an annual basis and include the indicators of annual financial statements of all participants in the group, on the other hand - monitoring compliance with economic standards banking group. In our opinion, the establishment of interim forms of consolidated financial statements is one of the urgent issues for further improvement of consolidated supervision and the development of methodological provision of remote monitoring by the National Bank on the activities of banking groups.

As noted above, the issue of remote monitoring of the activities of banking groups and banks participating in banking groups remains unclear to date. It should be noted that the peculiarities of monitoring for such a subject of oversight are due primarily to specific risks generated by the activities of banking groups, which, in our opinion, can be divided into specific and general ones. General risks include credit, interest, currency, liquidity risk, operational and technological, legal and others, but within the banking group may receive much more attention in the risk management system of individual banks-participants in the banking group. Specific risks include:

- the risk of «spreading», which can significantly affect the financial position of the bank and arises from the participants of the banking group, especially non-bank type, which are not subject to supervision, similar to banks. Thus, the realization of risk is possible both through the mechanism of open positions of participants of the banking group (for example, lending to related parties), or because of the spread of unfavorable information to the bank or the loss of business reputation of one of the group members;

- organizational risk associated with the functioning of the banking group in the form of a complex structure with a significant number of interconnections («cross-ownership»), which greatly complicates the monitoring procedure;

- the risk of the quality of consolidated management that may arise as a result of the failure of the responsible person of the banking group and / or the banking group as a whole to ensure coordination of actions and the adoption of sound management decisions, absence of conflict of interests among the group members and sufficient level of control over operations of the banking group.

Within the framework of the proposed multi-level study of the multi-level monitoring system for the activities of banks we propose for banks-objects of the basic monitoring regime to consider adequate control on a periodic basis based on the economic standards of the banking group and the analysis of consolidated annual financial statements. While for banks-objects of the enhanced monitoring regime and at the same time the bank-group participants it is expedient to implement banking supervisory bodies, in particular prudential oversight, such key aspects (aspects) of monitoring as organizational (O - organizational aspects), financial ( $\mathrm{F}$ - financial aspects, R-risk aspects and I-interaction and influence aspects, or OFRI (Fig. 3). 


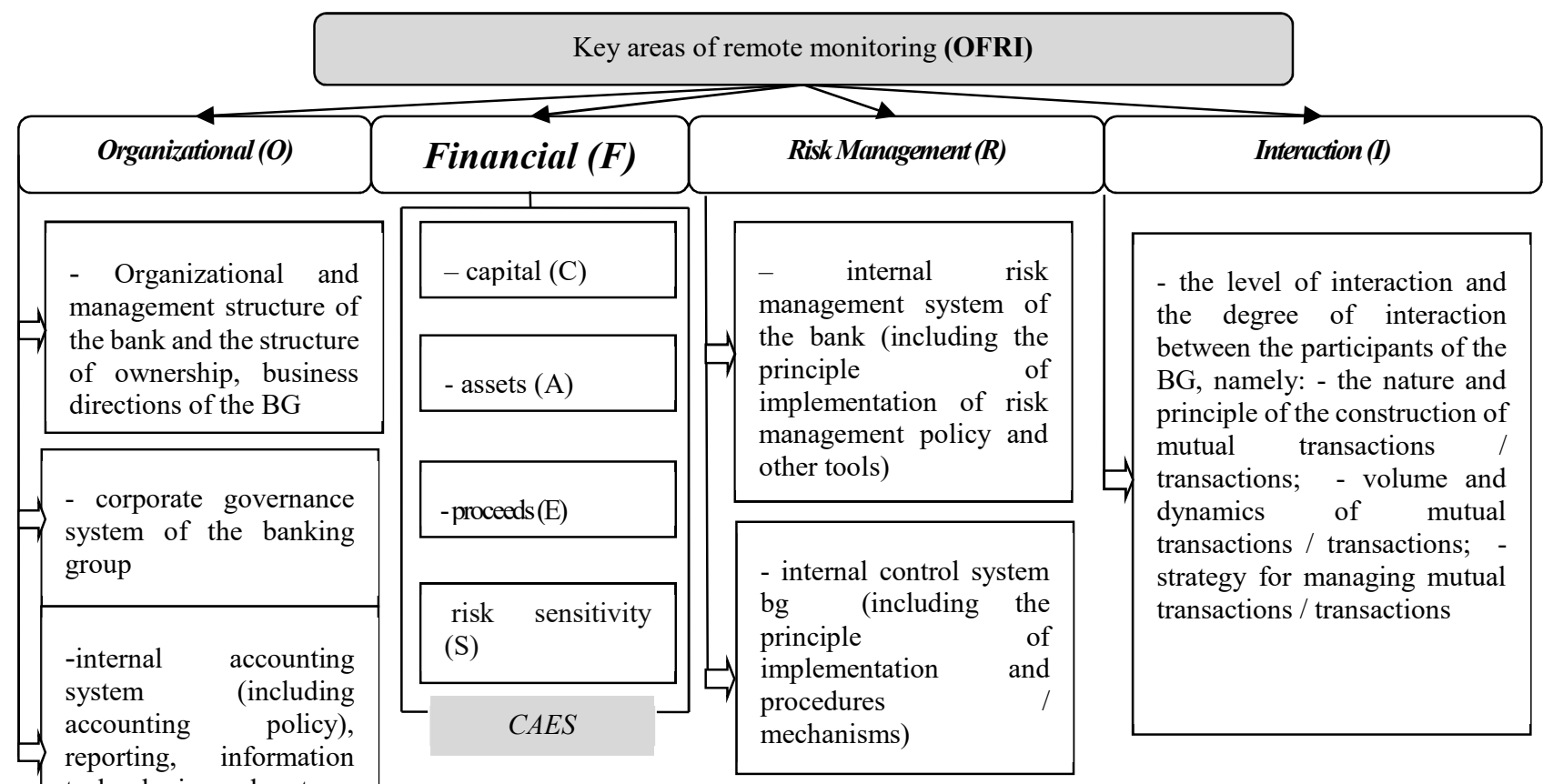

Fig. 1. Structural and logic scheme of carrying out stress testing of banks as a tool for enhanced remote risk-based monitoring over the activities of banks

The first direction of remote monitoring by the National Bank according to the bank-participant of the banking group should be focused on the organizational features of the functioning of the banking group, in particular:

- the internal construction of the banking group and the principles of its functioning (the organizationalmanagement structure of the banking group is investigated, including information on all shareholders, ownership structure and analyzes the main business lines of the bank, their shares and dynamics);

- the system of corporate governance (the existence of internal corporate governance policies, including remuneration systems, the composition and structure of the Supervisory Board of the Bank and the Board, the level of their professional suitability and business reputation, the division of functional responsibilities within the structure of the banking group);

- the internal accounting and reporting system (banking group accounting policy, responsible persons / units for compliance with it, and compliance with International Accounting and Reporting Standards, banking group controlling system and composition / structure of main internal reporting forms) and features of the information system and technologies that used by the group (informational architecture supporting the operations of the group and its version, the degree of protection of internal information, the presence of specialized (profile) committees $\mathrm{s}$ and departments, including verifiable fact checking internal audit group of such units and, accordingly, the report analyzes internal and external audit on the state of information technology in the banking group).

The next line is designed to find out the financial position and financial performance of the banking group and presented by the CAES system, which is based on the CAMELS rating system for assessing the financial condition of the bank. Within the framework of the first component - C (Capital) - the adequacy of the capital of the banking group is established, its adequacy is investigated (observance of capital standards Н3к and Н3$1 \kappa)$ and quality (structure and structure of capital, its change in dynamics), strategy of distribution of capital in the middle of banking group and factors taken into account when allocating capital in a group, internal limits and limits on capital movements, dividend policy of the group. The second component of the financial direction of the monitoring - A (Assets) - primarily involves determining the level of problem (overdue) debt and, accordingly, assessing the quality of assets of the banking group, their volume, dynamics and structure, analyzing compliance with liquidity norms (N5k and N6k), examining credit policy groups and its key priorities). Component E (Earnings) involves analyzing the financial results of the group (income and expenses, their volume, dynamics, structure), the level of profitability in general (assets, capital of the group) and individual members of the group and business areas. The last component of S (Sensitivity to risks) is 
aimed at assessing the sensitivity of the banking group to the main banking risks - credit (including compliance with the norms of credit risk $\mathrm{H} 7 \mathrm{\kappa}, \mathrm{H} 8 \kappa, \mathrm{H} 9 \kappa, \mathrm{H} 10 \kappa, \mathrm{H} 10-1 \kappa)$, currency, interest, market, liquidity risk, operational-technological, strategic, legal, etc.

The third area of remote monitoring must be devoted to:

$>$ internal risk management system of the banking group. In particular, the existence of an internal risk management policy for the group is analyzed, including Principle of implementation of risk management policy of the banking group - centralized or decentralized, mechanisms and tools for identification, regulation and control of risks, composition of internal reporting on risk groups, availability of specialized committees and subdivisions, incl. the fact of verifying the internal audit service of the group of such units is verified and, accordingly, analyzing the internal and external audit reports regarding the state of risk management in the banking group); the system of internal control in a group, namely, the principle of the implementation of internal control in a group (centralized / decentralized) and procedures / mechanisms of control, including system of internal restrictions and limits, determines the existence of internal and external audit policies, principles of their work and reporting).

The last direction of remote monitoring should focus on the aspects of interaction and interaction between the participants in the banking group, due to the presence of the above-mentioned risk of «distribution». Particular attention in this case requires the definition of the level of interaction and the degree of interaction between the members of the group, namely the nature and principles of the construction of mutual transactions / transactions; the volume and dynamics of mutual transactions / transactions are studied, the strategy of management of mutual transactions / transactions, open positions of the participants of the bank (including analysis of compliance with the norm of participation (investment) N11k and H12k).

\section{Conclusion}

According to the results of the analysis of these areas by the supervisory authority on prudential monitoring on the basis of a specially developed report form or questionnaire, which is submitted on a periodic basis, the conclusion is reached on the overall assessment of the status of the banking group and its potential impact on the activities of the bank - a participant in the banking group and, at the same time, the object of the reinforced supervision. Thus, according to the authors, the above suggestions regarding the application of the elements of consolidated supervision within the framework of remote monitoring of the activities of banks - participants of banking groups will allow, firstly, to take into account the current trends in the development of domestic banking business, in particular, the functioning of banking groups and increased bank risks, related to this process, and secondly, to provide really strengthened supervision of banks that are characterized by a high level of aggregate risk profile of the bank and medium (or significant $\mathrm{m}$ ) degree of influence on financial stability of the country.

For purposes of the guidance, "stress testing" refers to exercises used to conduct a forward-looking assessment of the potential impact of various adverse events and circumstances on a banking organization. An effective stress testing framework provides a comprehensive, integrated, and forward-looking set of activities for a banking organization to employ in order to assist in the identification and measurement of its material risks and vulnerabilities. Material risks and vulnerabilities may manifest themselves during stressful economic or financial environments, or arise from firm-specific adverse events. A banking organization should develop and implement its stress testing framework in a manner commensurate with its size, complexity, business activities, and overall risk profile.

\section{References}

1. Hendricks D. (2009). Defining Systemic Risk. The Pew Financial Reform Project. Retrieved from: http://www.pewtrusts.org/our_worl.aspx?id=3242.

2. Nelson, Wayne B. (2004), Accelerated Testing, Statistical Models, Test Plans, and Data Analysis, John Wiley \& Sons, New York, ISBN 0-471-69736-2

3. Bank Stress Test. Retrieved from http://www.investopedia.com/ terms/b/bank-stress-test.asp

4. G.A. Capolino H. Henao G. Cirrincione R. Grisel T. Assaf G. (2001). Ekwe. Monitoring and diagnosis of induction machines in the University of Picardie: present and future. Proceedings International Symposium on Diagnostics for Electrical Machines Power Electronics \& Drives, 111-117.

5. Herring R. (2005). BCCI \& Barings: bank resolutions complicated by fraud and global corporate structure: Retrieved from: http://fic.wharton.upenn.edu/fic/papers/05/0518.pdf. 
6. Hirtle B. (2009). Macroprudential Supervision of Financial Institutions: Lessons from the SCAP. Federal Reserve Bank of New York Staff Reports, 13-61.

7. Increasing the Intensity and Effectiveness of SIFI Supervision. Retrieved from: http://www.financialstabilityboard.org/publications/r_121031ab.pdf.

8. Intensity and Effectiveness of SIFI Supervision Recommendations for enhanced supervision [Electronic resource]. Retrieved from: http://www.imf.org/external $/ \mathrm{np} / \mathrm{mcm} /$ financialstability/papers/sifisup.pdf.

9. International Convergence of Capital Measurement and Capital Standards. A Revised Framework Retrieved from: http://www.bis.org.

10. International Convergence of Capital Standards. Basel Committee on Banking Supervision. Retrieved from: http://www.bis.org.

11. Kaminsky G. (2000). The leading indicators of currency crises. National Bureau of Economic research, 63, 316-341.

12. Karas A. (2009). The Effect of Deposit Insurance on Market Discipline: Evidence from a Natural Experiment on Deposit Flows. Middlebury College Working Paper Series, 9, 234-249.

13. Kaufman G. (1990). Are Some Banks Too Large to Fail? Myth and Reality. Contemporary Economic Policy, 8, 3-14.

14. Kaufman G. (2003). What is Systemic Risk, and do Bank Regulators Retard or Contribute to it? Journal of Political Economy, 1.7, 371-391.

15. Kupiec P. (2004). Assessing Systemic Risk Exposure from Banks and GSEs Under Alternative Approaches to Capital Regulation. The Journal of Real Estate Finance and Economics, 28, 14-23.

16. Lindgren C. (1999). Financial Sector Crisis and Restructuring. Lessons from Asia. Washington: Occasional Paper, 103.

17. Measuring the systemic importance of interconnected banks by Mathias Drehmann and Nikola Tarashev. Retrieved from: http://www.bis.org.

18. Nelson P. (2001). Transparency mechanisms at the multilateral development banks / P. Nelson // World dev, 29(11), 1835-1847.

19. Newman P. (1992). The New Palgrave Dictionary of Money \& Finance (in 3 volumes). London: Macmillan Press Limited, 865.

20. On Systemically Important Financial Institutions and Progressive Systemic Mitigation. Retrieved from: http://www.clevelandfed.org/research/policy/pdp27.cfm.

21. Dodd-Frank Wall Street Reform and Consumer Protection Act. Retrieved from: http://www.cftc.gov/ucm/groups/public_enrolledbill.pdf.

22. Domestic systemically - important banks. Retrieved http://www.apra.gov.au/Publications/Documents/Risk202012.pdf.

23. Enhanced Risk Disclosure by Banks. Retrieved from: https://www.financialstabilityboard. org/publications /r_121029.pdf.

24. Enhancing Financial Stability and Resilience: Macroprudential. (2010). Policy, Tools, and Systems for the Future. Group of Thirty. Retrieved from: http:/www.group30.org/images/PDF/ Macroprudential Report.pdf.

25. European Central Bank Report (2010). Recent Advances in Modelling Systemic Risk Using Network Analysis. Retrieved from: http://www.ecb.europa.eu/pub/pdf/other/modellingsystemicrisk012010en. pdf?d216f976f3587224bcc087cc8149ed49.

26. European Systemic Risk. Retrieved from: http://www.esrb.europa.eu/about/background/html/ index.en.html.

27. Freeman R. (1984). Strategic management: A stakeholder approach, Boston: Pitman, 276.

28. GAMMA Score e-Brochure. Retrieved from: http://www.standardandpoors.com/aboutsp/gamma/en/eu. 